\title{
Corpo em devir
}

\section{Luiz Fuganti}

○

devir - eterno e necessário vir-a-ser, que torna a existência necessária e enquanto tal nos atravessa, constitui e sustenta toda a natureza. Ele, além de causa de si, é também o único substrato que engendra o corpo. Mas, apesar de jamais deixar de atravessálo e de engendrá-lo, o devir e os processos de diferenciação que o produzem nos escapam sempre mais à medida que a vida humana, na condição atual, avança. Assim, vamos nos perdendo de nós mesmos e do corpo próprio do desejo, daquilo que deseja em nós. Nosso modo de vida é o inimigo fundamental. Há séculos, há milênios, e a cada nascimento ou ciclo de vida, essa história se repete. Os tempos acumulados da humanidade e os procedimentos atuais de geração de consciência não param de se cruzar. Camadas e linhas de tempos e movimentos dobrados coexistem, se condensam e se dilatam em nós, em nosso corpo e pensamento. Uma pluralidade de devires e de movimentos quebrados que não só são os do corpo penetrado de acontecimentos vividos, mas também os do corpo ramificado da humanidade, com toda a pressão virtual da memória que subsiste nele e faz-se continuar no que está por vir. As formações humanas, através de seus modos de viver e de pensar, inventaram e ainda conservam e cultivam uma tendência em investir e aplicar tempos e movimentos que nos afastam cada vez mais do gosto pelas experimentações criadoras. Ainda que, com o protesto do nosso corpo intenso, desconfiemos do que poderia ser um modo de pensamento afirmativo, desejante das potências de variar e instaurar novas dimensões existenciais. Com isso continuamos nos afastando também, cada vez mais, da capacidade de acontecer. Acontecer como produção de realidades inéditas, numa experimentação direta, sem o piedoso comando das estruturas da representação humana. Eis o foco problemático que sugiro trabalhar aqui.

Nós geralmente vivemos, por mais paradoxal que isso possa parecer, de modo a nos separar do que podemos. Nós não sabemos muito bem mais o que é vivermos colados à capacidade de existir na sua abertura máxima ou, no mínimo, na sua abertura que faz a nossa potência crescer. Esse horizonte é cada vez mais ofuscado. Eu diria mais: há uma instituição humana que investe cada vez mais na separação da vida do que ela pode; e falsifica o que é viver; assim também falsifica o que é pensar. E não se sabe mais da vida a não ser longe do imediato, a não ser fora do acontecimento. Não se sabe mais o segredo de um modo de vida verdadeiramente

Luiz Fuganti é filósofo, arquiteto e escritor. Fundador da Escola Nômade de Filosofia. 
ativo, afirmativo da diferença que produz real, que faz do durar um gosto continuado e colado a uma diferenciação intensiva. A gente sabe, geralmente, de uma vida reativa, que se ressente das variações sofridas nos encontros, que padece das multiplicidades, que só tolera a diferença operando de maneira domesticada, bem intencionada, previsível, conciliada, rendida pelo consenso no mau uso da dor. Parece que só se é capaz de conceber uma vida cujo horizonte é negativo, cujo tempo é um tempo aniquilador, cuja idéia da morte é uma idéia de degenerescência pela matéria ou pelo desejo.

Nós não sabemos mais também o que é agir intrinsecamente num devir constituinte de nós próprios, nem como engendrar o necessário ponto de vista que faz conquistar uma capacidade de auto-geração do valor e que é, em última instância, a realização imanente da própria potência que nos constitui e que nos faz viver. Geralmente agimos por determinação extrínseca, mesmo e principalmente quando acreditamos que conquistamos uma autonomia moral de sujeitos legisladores ou de profissionais competentes, autorizados e autorizadores, porque, como diz Nietzsche, moral e autônomo se excluem. Chamamos a isso ação, mas ignoramos a causa real do que nos determina a agir, a reagir, a pensar, a acreditar, a desejar.

Nesse sentido, de um ponto de vista de quem exerce certo tipo de liberdade real, isto é, de quem efetua e preenche a própria potência com encontros que fazem a diferença, eu diria que para esse, a idéia de um corpo em devir seria uma redundância, porque - poderia ele nos perguntar - haveria alguma coisa fora do devir? O corpo estaria fora do devir? O pensamento estaria fora do devir? Diríamos nós que é impossível alguma coisa, algo ou alguém estar fora do devir! O devir não é um acidente na existência, o devir é constitutivo da própria essência. Sem ele não haveria nem o ser, nem a existência, muito menos a auto sustentabilidade no existir. $\mathrm{O}$ devir é um campo constitutivo, não só da experiência vivida, como da produção da eternidade. A eternidade se produz no devir.
Fica esquisito, então, a gente afirmar que existe um corpo separado do devir, se nada se sustentaria nem continuaria fora do devir! A nossa idéia é de que, conforme Spinoza, só o homem separado da potência de pensar, portanto passivo e reduzido ao conhecimento por imagens, poderia acreditar e investir em um ser que transcenderia o devir! Assim também pensa Nietzsche, que vislumbra aí a projeção sobre a natureza de uma imagem invertida, engendrada como reflexo de um devir reativo das forças do corpo que entra em decadência. O corpo segue em devir, mas o horizonte torna-se um horizonte niilista.

Nietzsche distingue estágios de niilismo. Ele atribui à idéia de niilismo alguns sentidos que se encadeiam, que se sucedem na história e coexistem no presente. Um deles é o niilismo negativo. $\mathrm{O}$ niilismo negativo não é um nãoser, é antes um valor de nada que a vida toma, que a existência, que a natureza, que o desejo, que o movimento, que o tempo e o espaço enfim, que o corpo e os afetos tomam. Há sempre no niilismo uma desqualificação do corpo, um pressuposto de que a existência tem alguma carência que a torna imperfeita, de que existir é desejar e desejar é ter falta de objeto. E, nesse sentido, o homem, separado da capacidade de existir, busca, desesperado e confusamente para escapar dessa existência cuja falta de preenchimento é traduzida por uma consciência devedora -, um elemento superior, um valor superior à vida, um valor superior à existência. Desse modo não se diz diretamente "não" à vida, não se diz "não" à natureza, não se diz "não" à Terra, mas se diz "sim" a um ideal, "sim" a um outro mundo, ou até mesmo "sim" a um sonho de vida - os publicitários tomando o lugar dos velhos sacerdotes. Mas essa é a mentira do ideal, essa é verdadeiramente a maneira de dizer não à vida, de desqualificar o corpo, o desejo e o pensamento. E essa também é a maneira mais básica, de um ponto de vista formal relativo ao uso da linguagem - de submeter a expressão da vida à representação moral, à lógica de um investimento de forças gregárias, 
coletivamente determinado; de separar a vida do que ela pode, ou de descolar o corpo do seu tornar-se ativo e o pensamento do seu tornar-se afirmativo, para entregá-los a um devir reativo controlado por um sistema de julgamento divino ou humano.

$\mathrm{Na}$ medida mesma em que nós perdemos a capacidade de acontecer, nós não sabemos mais qual a fonte ou o motor do nosso desejo. Não sabemos mais qual é a fonte ou o motor do movimento do corpo. Perdemos o sentido das velocidades e lentidóes, dos seus fluxos que redistribuem o desejo. Não apreendemos mais, senão confusa e indiretamente, as modificações que afetam um corpo intensivo e o fazem muda seu destino. O que nos escapa então é a natureza operando em ato, constituinte de um campo afetivo. O que nos escapa então é aquilo que, no corpo, produz afetos e, também, o primeiro dos afetos, o desejo, ao colocar sua potência de composição em variação através dos encontros e processos dos quais participa. A fronteira, o extremo do meio, aquilo que ganha vida através de nós ao tocar a ponta do espaço, ao tocar com sua pele física o próprio ser do sentir, o percepto do perceber. $\mathrm{Na}$ medida que ressentimos o acontecimento, o corpo perde a sua fonte, não só material, mas também temporal. Não sabe mais inventar um jeito verdadeiramente próprio para um devir auto-sustentável. Nem se auto-modificar, nem se auto-regular. Torna-se impotente para modificar-se a si mesmo e fruir das coisas modificadas que resultam dessa própria efetuação.

Por outro lado, nesse processo de desqualificação do acontecimento sempre inédito, também o pensamento se separa da capacidade de acontecer e de criar no tempo um tempo imediato que o atravessa. Ele perde, digamos assim, o aspecto inovador, a superfície imediata do tempo. Ao perder o próprio meio ou conexão com o devir, ele perde o frescor do acontecimento sem o qual o pensamento não se cria a si próprio, não cria ao conhecer.

Então nós nos separamos simultaneamente da capacidade de acontecer no corpo e da capacidade de acontecer no pensamento. Nos separamos da capacidade de exercer a sensibilidade, de ativar os elementos intensivos do corpo; assim como da capacidade de afirmar o pensamento sem a instância da representação, do eu ou da consciência. Nós, ao contrário, colocamos a consciência como mediador imperativo do corpo e do pensamento. Mas cometemos essa inversão atribuindo à consciência uma espécie de eminência sem a qual, acredita-se, a alma seria tragada pelo corpo em devir, fonte de sua perdição. E este corpo de fluxos comprometeria seu resgate ou salvação, pois o corpo não organizado, não sendo preenchido de finalidade ou sentido para o bem, deixaria também a tutela de uma instância que pretendia representá-lo perante seu tribunal - instância que seria inútil sem a dobragem e a traição do corpo em devir.

Nós penhoramos o corpo sob uma consciência reativa, devota e passional. Penduramos o pensamento no teto circular das belas significações. Abortamos o pensar e etiquetamos o real ao colocar em seu lugar uma cadeia de signos de linguagem. Tal rede estrutural de significação, ao mesmo tempo em que enclausura o desejo na interioridade do sujeito, traga o pensamento na gravitação inelutável de um buraco negro, o de uma dívida infinita. Má-consciência, diria Nietzsche, ilusão do livre-arbítrio ou dos decretos livres, diria Spinoza.

Assim buscaríamos maneiras de nos ligar novamente ao que podemos e de reconquistar as potências do corpo, de abri-lo ao que pode. Ensaiamos retomar a abertura do desejo e inventar um pensamento afirmativo e abrir-se a todo o seu vigor, a força do que ele pode. Mas, uma vez que estamos impotentes no pensamento, impotentes no corpo e impotentes no desejo, é do seio dessa impotência mesma que emerge uma vontade de poder, um desejo de poder, um desejo de se religar tristemente àquilo que perdemos. E como, artificialmente, fomos separados do que podemos, do ponto de vista do desejo, do corpo e do pensamento, também, artificialmente, nos ligamos a esse poder pela 
invenção de um espelho, pela invenção de uma superfície de reconhecimento, por um rebatimento que nos faz existir através do olhar do outro, através da aceitação do outro, e que nos ameaça e condena ao ostracismo sob a rejeição do Outro.

Nós criamos, digamos assim, um espelho na medida em que produzimos um rosto em nós. $\mathrm{O}$ espelho da sociedade é o nosso próprio rosto, o modo como o nosso rosto se molda, gera, emite signos, recebe signos e se torna o porta-voz de vozes, da nossa escrita, da nossa leitura, da nossa interpretação. $\mathrm{O}$ rosto como uma substância iniciativa que autoriza ou desautoriza, que institui ou desinstitui a consciência ou o pensamento submetido à consciência e o corpo obediente ao organismo. Nós acabamos por perder o corpo, ou o que diz Artaud: nós perdemos o corpo pleno, sem órgãos, que não necessita, não dos órgãos, mas de uma organização para os órgãos que faz perder exatamente essa capacidade autogerativa e autônoma do corpo, talvez da mesma maneira como perdemos a capacidade autogerativa e criativa do pensamento. E com isso, uma vez que nós perdemos a capacidade de acontecer, nós investimos num ideal. Esse ideal inicialmente tem a altura de Deus, tem altura do outro mundo, tem altura de uma transcendência que não encontraríamos na existência exatamente pela perfeição ou pelo acabamento, ou pela eterna identidade circular que a experiência inviabilizaria. Evidentemente seria algo que estaria fora da natureza, mas esse algo fora da natureza é um mero pretexto, é uma mera desculpa, um mero sintoma, não é causa de nada, o mundo verdadeiro, o outro mundo, o mundo de Deus. $\mathrm{O}$ mundo ideal na verdade é um pretexto, é um instrumento, é um meio exatamente fictício para atribuir ou destituir valor ao corpo e ao pensamento, é uma instância de julgamento. Na verdade, pelo investimento num modelo, pelo investimento na identidade, pelo investimento num ideal, pelo investimento em Deus, pelo investimento num estado espiritual nós simplesmente nos servimos de uma máquina de desti- tuir o corpo e o pensamento da sua autonomia. Nós dizemos que, através desse valor essencial e verdadeiro, nós podemos medir o valor do corpo e do pensamento. Então, dessa maneira, nós fundamos a representação. A representação é um lugar privilegiado de re-apresentação das coisas imediatas. Nós precisamos mediar as coisas imediatas que não são auto-suficientes, que não são dignas de seu modo próprio de acontecer, que tem uma relação muito próxima com o caos. Essa, evidentemente, é uma visão religiosa, uma visão teológica, uma visão metafísica, uma visão moralista, mas, pra falar como Nietzsche, o ideal ascético, ou simplesmente esse aspecto do niilismo negativo é apenas, digamos assim, uma espécie de primeira instância, ou primeira desculpa que precisa levar a cabo uma empresa de acusação generalizada da vida. Acusação generalizada em relação a que exatamente? Em relação a forças, a potências, a intensidades, a movimentos, a tempos que não têm intencionalidade alguma, que não funcionam por finalidade, que não tem um objetivo de chegar a um alvo superior que os resgataria, porque tem um modo próprio de acontecer no imediato sem o que não realizam, não efetuam a sua própria natureza e não transmutam. Então, essa grande empresa, essa política do ódio, digamos assim, que é uma instituição humana, uma invenção humana - e os homens se agarram a isso como uma salvação -, é exercida de modo sistemático, não simplesmente por poderes exteriores a nós, mas por nós mesmos. Nós somos cúmplices dessa política. Colocamos nosso corpo a serviço desse organismo, destituímos o nosso corpo do devir propriamente ativo e o introduzimos ou entregamos de bandeja a um devir reativo, que busca simplesmente a conservação de si e que póe a questão criativa como secundária. A criação, no melhor dos casos, só passa na medida em que é posta a serviço da conservação: há uma inversão radical aí. $\mathrm{Na}$ mesma medida que quando pensarmos acreditando que só podemos pensar verdadeiramente, legitimamente, cientificamente a partir de um modelo, de um molde, de uma moldura e 
também de um modelador, sem o que nossas idéias não pareceriam de verdade. Introduzimos uma finalidade para o próprio pensamento, imaginamos um pensamento pensado a partir de um sujeito, a partir de uma consciência, que tem começo e uma finalidade; imaginamos que o meio, o processo, o devir, é apenas meio de chegar a esse objetivo. Penhoramos a nossa vida e a colocamos a serviço de um projeto, a serviço de uma finalidade. Perdemos novamente a capacidade de criar e desperdiçamos o inédito do que a existência nos oferece a cada momento, a cada entretempo que está subjacente, que subsiste e que insiste nos preenchimentos das significações. Então vamos entupindo nossa capacidade, nossos modos de fazer o pensamento fluir e passar, vamos entupindo esses modos, essas pontes, essas passagens, essas janelas, essas portas, esses poros, com as significações e, a medida em que vamos investindo nossas significações, vamos também nos afundando cada vez mais num buraco que se pretende autorizado para interpretar, para transmitir e para observar e cuidar da aplicação dessas significações. Vamos nos transformando em sujeitos ou legisladores vigiados por um modo de "deverser” que já se introjetou em nós. Nesse ponto de vista a gente atinge o segundo aspecto do que Nietzsche chama de niilismo, que é o niilismo reativo, quando a gente vai organizando de modo tal essa empresa, essa política do ódio de acusar tudo aquilo que não tem finalidade, que não tem responsabilidade, que tem uma inocência essencial. Uma vez que há uma omissão, uma separação, um envenenamento na atmosfera do acontecimento. Deus não tem mais a menor necessidade, o tirano não tem mais a menor necessidade, os regimes de soberania não têm mais a menor necessidade e nós passamos agora a investir nos valores do homem. Colocamos o homem no lugar de Deus, e achamos que fizemos grande coisa, quando na verdade apenas ocupamos o velho lugar de julgamento, apenas reformamos o lugar de julgamento. Agora dizemos assim: o juiz tem a estatura do homem, nós não precisamos mais de Deus. Falamos junto com Hegel, dizendo assim: o homem estava alienado em valores divinos, o homem estava alienado em valores de outro mundo, mas esses valores divinos, de outro mundo, eram apenas valores humanos. Esses universais abstratos em si na verdade eram universais que o homem inventou para si. Portanto, temos que de novo resgatar e buscar esses universais em si e transformá-los em mudanças concretas para o homem. Essa é a grande revolução hegeliana e um certo marxismo investiu também nesse modo dialético de pensar. A idéia de desalienação, embora tenha um caráter materialista, não rompe a sua filiação com o ressentimento. Inventou-se então, o homem e os valores do homem, o homem e os direitos do homem, como se então o homem finalmente fosse capaz de conduzir o próprio destino, mas o destino desse homem nada mais é do que o destino do velho homem cansado, agora mais organizado, mais anestesiado, mais satisfeito, mais feliz, o homem que não precisa mais da salvação, agora ele tem a felicidade, não precisa mais da eternidade, agora ele tem o progresso e a revolução, não precisa mais do tirano, do rei que comande a todos, agora ele tem a democracia, não precisa mais de Deus, agora ele tem a lei, uma só lei e uma vontade geral, como dizia Sade, uma vontade geral de vidas que já não sabem mais acontecer. E nessa medida, vidas que não sabem viver sem a lei, vidas que são capazes de fazer aparecer o que? Monstros, forças do mal, forças criminosas, como diria Freud, incestuosas e parricidas - todos os padres que fazem coro hoje em dia, os psicanalistas, mas também os publicitários, enfim, tantos outros que, inclusive, se servem da arte para anestesiar. Hoje em dia a arte também ocupou, junto com as terapias e com as igrejas, o lugar de tornar a vida miserável mais suportável. Então nós não buscamos mais a concentração, a intensificação, o tensionamento: nós buscamos a direção, nós buscamos o descuido de si. Olhar para o lado, olhar para o próximo, mas olhar dentro só para reconhecer melhor que somos impotentes. Agora, será que a gente é capaz de olhar dentro e 
chamar os fantasmas, os monstros, as forças criminosas, as forças malévolas para brincar?

Eu diria que os devires ativos foram transformados em devires monstruosos, em forças monstruosas, a ponto de o homem não mais admitir que pode viver sem lei, que pode viver sem moral, que pode viver sem Estado, que pode viver sem Deus, que pode viver sem o eu, sem o ego, que pode viver sem o sujeito, que pode viver sem a significação. Não que nós devamos simplesmente jogar isso tudo fora. É simplesmente aprender o lugar de onde isso vem e como nós investimos nessas coisas, e como a gente é cúmplice de tudo isso, e como a gente investe na democracia. E esse termo, esse conceito de democracia que, geralmente, temos medo de afrontar por podermos ser chamados de autoritários, de nazistas, de fascistas ou de empregadores de uma ordem aristocrata, não há forma mais autoritária e fascista, fingida e escondida, do que a democracia e a lei. Não existe nenhuma diferença de natureza entre a lei civilizada e a barbárie terrorista: o terrorismo e a barbárie, junto com a lei e a civilização, têm a mesma fonte. Não há barbárie, não há monstruosidade, não há crime sem essa produção social da monstruosidade a partir da incapacidade de tolerar os devires ativos do corpo. Então nós somos socialmente educados, codificados, historicamente investidos a cultivar uma forma de organizar o corpo, uma forma de organizar o pensamento, sem a qual o homem cairia num abismo, sem a qual as forças do homem, as mais caóticas, tomariam conta e a vida se perderia, naquilo que Hobbes chamou de um estado de guerra de todos contra todos, uma vez que só observaríamos as paixões individuais e na individualidade só haveria esse tipo de paixão de rapina, de transição, de destruição, porque só pensaríamos no interesse individual. Esse pressuposto, então, que as forças do corpo, as forças do pensamento têm uma deficiência de autoregulação de ordem própria, é o pressuposto de todo poder junto com toda a vida impotente. Não há poder sem vida impotente, a vida impotente é uma condição do poder, o poder cul- tiva a vida impotente, ele cultiva essas paixões, e toda a vida impotente busca o poder. Há uma cumplicidade entre a vida impotente e a busca pelo poder e o exercício do poder. Não há poder que não seja sempre exercido, Foucault já dizia isso muito bem, pelos dominados e pelos dominantes. $\mathrm{O}$ poder não está no palácio tal, na realeza tal, na instituição tal, no aparelho de estado tal: ele é sempre exercido e atravessa todos os corpos. E de que modo ele é exercido? Pela nossa sensibilidade e pela nossa linguagem. $\mathrm{O}$ uso que fazemos da nossa sensibilidade e da nossa linguagem atravessa modos de poder. Através do uso da na nossa sensibilidade a gente separa o nosso corpo do que ele pode, através do uso da nossa linguagem a gente separa o nosso pensamento do que ele pode. Nós investimos o pensamento, submetemos o pensamento a uma representação. Nós submetemos o corpo a um organismo. Nós perdemos a capacidade de acontecer no imediato porque achamos que isso tudo é uma efemeridade, que o acontecimento é um mero acidente, que o acaso não tem nenhuma necessidade, que o devir não tem nenhum ser, que essa multiplicidade caótica não tem nenhuma unidade. Então nós investimos numa unidade e numa necessidade, num ser, numa essência, numa identidade que nos resgataria. E esse investimento mesmo é o que, ao mesmo tempo nos apazigua, nos dá o sentido do nosso sentimento em vão. No fundo ele é um sofrimento humano feito de falsos problemas, um desperdício só, porque nós não sabemos mais sofrer, não sabemos aproveitar a dor. Levamos a sério a dor, somos demasiado sérios e responsáveis diante das injustiças, somos extremamente sensíveis diante de naturezas dolorosas em relação ao que ameaçaria uma existência que já está podre na sua essência, ao invés de investirmos na capacidade de adubar a nossa própria terra, de revolver o solo que já está empedrado, onde semente alguma mais brota em nós. Será que a gente é capaz de fazer de nós mesmos um arado que are essa terra que já está sem oxigênio? Será que a gente é capaz de arejar a nós mesmos? Para isso 
é necessário ser também destruidor, é necessário ser assassinos de nós mesmos, destruir a parte de nós que está podre, que deve ser morta e honrada até. Chorar, fazer o luto necessário e dizer adeus e alegrar-se quando se ultrapassa novamente essa condição de afundamento, de decadência. Ou seja, nós somos muito piedosos conosco, nós não somos ainda capazes de aprender o não necessário. Somos educados para dizer sim e para ser amável e o nosso sim só é permitido na medida em que a gente diz um não fundamental, um não inconfessável que destitui a vida da sua capacidade de acontecer. Então a gente diz um sim que na verdade esconde esse não fundamental e não sabemos mais dizer não a esse não fundamental que separa a vida do que ela pode. Então, como diz Nietzsche: não sabemos nem dizer sim e nem dizer não. $\mathrm{O}$ nosso sim é um falso sim porque afirmamos valores que oneram a vida, que tornam a vida pesada, incapaz de dançar, incapaz de acontecer, incapaz de fluir e nós, ao mesmo tempo em que oneramos a vida, investimos ainda mais numa salvação que estaria sempre no futuro ou, no caso dos pessimistas, que já foi, que está perdida, num paraíso que não volta mais. Nossa vida fica entre a memória e o projeto, mas nunca no devir. Nunca somos capazes de fazer a nossa plenitude, a nossa eternidade aqui e agora sem falta, saber que o caminho é pleno, que é no caminho que existe a plenitude, que a plenitude não está no fim e nem na origem, que não estamos indo em direção a nenhuma unidade original e nem a uma totalidade final, que se existe ainda alguma idéia de salvação, a salvação é pelo meio. Pelo meio a gente é capaz de acontecer, mas a gente só é capaz de acontecer se a gente é capaz de reencontrar o virtual que atravessa o atual ou o existencial. Se a gente não encontra essa dimensão do virtual, que dimensão é essa? É o inesgotável de qualquer relação, o inesgotável no espaço, o vazio que nós não sabemos mais valorizar e transformamos todo vazio em nada, ou o entretempo que não sabemos mais valorizar porque há um tempo cronológico e necessário ao bom andamento das coisas e das tarefas a serem cumpridas e perdemos os entretempos que são destituídos como caóticos, como desviantes, como labirínticos, como condutores da loucura. Então perdemos o virtual do tempo, perdemos o virtual do espaço, perdemos o virtual da superfície, perdemos o meio de acontecer. Nós preenchemos essa impotência com referências e nos enchemos de referências e daí a gente até fala em nome de Nietzsche, de Spinoza, de muitos pensadores bacanas que estão na moda, Deleuze, Guattari, Foucault, Baudrillard, enfim tem uma série deles aí. Como se bastasse, simplesmente, a gente se servir deles. Às vezes é até uma forma de desespero: você busca aliados, busca algum tipo de luz porque há, de fato, um investimento sincero, honesto, na retomada da nossa capacidade de acontecer. Mas muitas vezes é trapaça, é negociação, muitas vezes é conquista e aprimoramento de um novo nicho de mercado, uma maneira diferente de falar que gera frutos, gera lucros, gera reconhecimentos. Enfim, a gente está sempre existindo pelo espelho que a gente é incapaz de quebrar e a gente cuida para manter o espelho sempre bem limpinho para ele refletir bem a nossa impotência, que é mascarada com o poder que a gente ganha a cada dia, com a competência.

Então eu diria que, assim como há uma política do ódio e o ódio implica tristeza, há um investimento essencial na tristeza, há um investimento essencial na desqualificação de nós mesmos ou uma impotência através do medo, através da clareza - temos um pensamento muito claro, científico, racional, temos muita tecnologia - através do poder, porque ele faz gozar o impotente e sempre acabamos sucumbindo num grande cansaço porque a morte tarda, mas não falha, como a justiça - são da mesma natureza essa morte e essa justiça. Assim como há uma política do ódio, há uma política da tristeza, que é compensada com o prazer - nós buscamos o tempo todo compensações. Nós somos estimulados a ter desejos, mas o desejo não pode ser exagerado, ele tem que ser comedido, é um pequeno desejo, é um meio querer, assim como 
o que ele ganha é um pequeno prazer. Meios quereres e pequenos prazeres. Não há hoje ninguém que ouse falar contra o prazer, não há hoje gente que fale contra as diferenças, contra as multiplicidades. São engraçadas essas coisas. Hoje em dia se fala em empoderamento das comunidades e ninguém desconfia; De graça, empoderamento? Como assim? E as comunidades mordem a isca. Por que? Porque elas são tão ingênuas assim? Será que ninguém sabe o que faz? Não. De fato, a vida separada do que pode, ela necessita disso, ela fabrica essa doença e oferece essa saúde, o modelo de saúde que faz com que essa doença seja reproduzida. A mesma coisa com o prazer: oferece esse prazer exatamente para manter o desejo em baixa intensidade. Desejo em alta intensidade é desejo sem intencionalidade, é desejo revolucionário, incomoda; ele de fato faz a diferença, e desejo que faça diferença não é tão interessante assim. Só é interessante se essa diferença estiver a serviço da demanda que o estimulou ou então que o capturou. A diferença não é de fato amada, a multiplicidade não é de fato amada, a mudança e o acontecimento não são de fato amados. No máximo são tolerados.

É essa autocrítica que eu quero convidar a gente a fazer. Esse rigor com a gente mesmo. Até que ponto a gente diz viva à multiplicidade, viva à diferença, viva à mudança, viva ao acontecimento? Quando, de fato, nós sofremos disso, nós padecemos disso, nós temos um entristecimento com isso, e vemos que não tem outra saída mesmo, então a gente vai inventar uma maneira de passar melhor com isso, apesar disso. Quando, na verdade, não existe outra essência, outra eternidade, outra necessidade, outra liberdade, outro gozo a não ser a afirmação plena do acontecimento. Então, essa incapacidade de dizer sim ao acontecimento só é uma incapacidade a partir de uma cumplicidade de quem está separado do que pode: ela é um investimento social. Há um investimento não só no ódio e na tristeza, como há um investimento num gozo e num prazer ou numa afirmação que reiteram a política do ódio e do entristeci- mento. Nunca o poder vai chegar e dizer que ele precisa da desqualificação da existência, mas não há poder sem essa desqualificação. Nunca o poder vai falar que vai odiar e entristecer, mas não há poder sem o ódio e sem a tristeza. Nunca o poder vai falar que a vida, ou que a natureza, é insuficiente, mas o poder só existe na medida em que ele cria uma instância que provê uma vida insuficiente. Nunca o poder vai, a não ser nas situaçôes limites e críticas, nos capturar pela dívida. Ele vai fazer o contrário, vai oferecer o crédito, vai oferecer a ajuda, vai oferecer o amor, o bem, a verdade, a paz, todos os valores que nós reclamamos, a democracia, os direitos (quanto mais direito melhor). De quê? Do homem. Quem é o homem? Não sabemos mais. Será que o homem é essa instância que tem uma vontade livre, que tem liberdade para escolher o bem e o mal, para evitar o falso e buscar o verdadeiro, para denunciar as injustiças e investir na justiça, para investir na utilidade ou desinvestir na nocividade? Será que é essa forma? É essa a forma interessante de ser? É essa a forma interessante de existir e de acontecer? Então será que a gente não vive um grande sono e investe nesse sono? E será que não seria interessante fazer como Nietzsche - não buscar aconselhar a humanidade ou até a nós mesmos a fazer outra coisa, mas acelerar o processo -, e dizer com ele : "bem-aventurados os que têm sono porque em breve adormecerão"? Por que a gente segue investindo em aconselhamentos, em ideologias, em verdadeiros sistemas, em referências? Não queremos outras referências? Fomos enganados?

A ciência está só ocupando o lugar da religião, mas ela tem o pressuposto moral. Qual é o pressuposto dela? É que a vida não vale por si mesma, é que existe um acaso e uma multiplicidade que devem ser recusados. Não somos todos moralistas, em última instância? Se quisermos o anarquismo, então abaixo o Estado, abaixo tudo, abaixo a lei. E será que o nosso anarquismo também não é uma forma de ressentimento? Eu estou provocando um pouco, mas não quero pintar nenhum quadro negro. 
Acho que quem pinta quadro negro quer oferecer salvação. Não é isso. Eu só quero me aproximar de certas nuances que não são suficientemente observadas por nós para liberar o lado potente do corpo e do pensamento. O que pode o corpo, o que pode o pensamento, o que pode a vida (uma vida afirmativa, uma vida ativa, uma vida criativa). Por que somos tão medrosos, tão covardes, investindo primeiro nas forças de conservação e não nas de criação? Porque a gente não sabe mais o que é criar. Porque pensamos que criar é só embaralhar as imagens e os códigos, dar uma mexida aqui e ali e já sai algo novo. Não sabemos mais criar produzindo eternidade, produzindo tempo próprio, produzindo espaço, produzindo vazio, produzindo corpo, produzindo elementos, produzindo realidades em última instância. Nós não sabemos mais que a própria natureza é usina de si e de tudo e que nós somos parte da natureza. Quem disse que o homem não é animal? Quem disse que o homem não é vegetal? Quem disse que o homem não é mineral? Nós somos parte disso tudo, nós estamos nessa imanência. Assim como a linguagem e o pensamento não são exclusividade humana. O homem tem a linguagem humana, mas existem outras linguagens, outros pensamento. A natureza pensa, não precisa do homem para pensar. Ao contrário, o homem pode ter inviabilizado o pensamento nele, porque existem forças em nós inteiramente positivas e plenas. O inconsciente é radicalmente inocente, não tem falta no inconsciente, não tem falta no desejo, o desejo não carece de objeto para se satisfazer, o desejo já começa na capacidade de acontecer, ele já é acontecimento antes de desejar em nós. E quando ele se efetua ele já é uma diferenciação e um ultrapassamento de si e ele não precisa de um objeto para se satisfazer: ele inventa o objeto dele. Assim nós deveríamos inventar o nosso mundo e a nossa realidade ao invés de buscar encontrar a realidade ou nos encontrar. Não tem nada para encontrar em nós e nem fora de nós. Precisamos inventar o que precisamos encontrar. Então é essa tomada de posição.
Eu diria, o corpo em devir ativo é aquele que toma parte no processo e se póe fazendo processo. Fazendo o que? Não só outras coisas: obras de arte, ciência, filosofia, funções, técnicas, objetos, mas fazendo a si próprio. O homem perdeu a capacidade de produzir a si próprio. Acomodou-se, acreditou que tinha uma forma natural: tem um eu e esse eu é natural, tem um objeto e esse objeto é natural, tem uma razão e a razão nos foi dada por Deus. Como diz Spinoza: "Deus, asilo da ignorância”. Então, que razão é essa? Essa razão sempre existiu? Ela foi inventada. Isso é um modo de pensar, é um modo, diria mais, de imaginar que essa razão que o homem inventou o separa da própria potência de pensar, assim como a sensibilidade orgânica. É natural do olho ver, mas quem inventou o olho? Não foi a luz? A luz existe sem o olho? Quem inventou o ouvido? Não foi o som? O som não é anterior ao ouvido? Não é um corpo sem órgãos antes dos órgãos, antes das funçōes? O que é o ouvido e o olho? O que são os órgãos, senão dobras intensivas de forças? Mas nós acreditamos que há um sujeito atrás do olho que faz ver, há um sujeito atrás do ouvido que faz ouvir, há um sujeito atrás da fala que faz falar, há um sujeito atrás do pensamento que faz pensar.

É essa existência nossa, nesse limiar, que nos faz reféns do medo e que nos faz investir na falsa clareza de uma certa ciência mistificada, e ao mesmo tempo ter esse fascínio pelo poder, pelo gozo, pelo reconhecimento, quando na verdade isso são apenas migalhas, são esmolas. Como diria Nietzsche, não somos suficientemente pobres para dar esmola: quem dá esmola é quem é pobre e quem recebe é ainda pior. Temos que dar presentes, temos que procurar aliados, temos que sair da situação de referência ou de seguidor. Temos que conquistar e afirmar as diferenças para que nos tornemos fortes. A força é a favor da liberdade. Essa idéia de que a força gera violência é a falsificação que o poder introjeta em nós. É exatamente porque somos fracos que somos violentos. O forte não é violento, o forte é generoso. $\mathrm{O}$ forte não toma, o 
forte dá, o forte gera, o forte cria. A idéia que temos de força é completamente deturpada. Nós precisamos reinventar a idéia de força e desinvestí-la da idéia de lei e de forma. Não precisa- mos da forma, precisamos inventar a qualidade da força e a qualidade da força é a afirmação da força ativa ou da força criativa. Isso seria um devir ativo para o corpo e para o pensamento. 